\title{
МОДЕЛИРОВАНИЕ СПОСОБОВ НЕСАНКЦИОНИРОВАННОГО ДОСТУПА К ИСТОЧНИКАМ КОНФИДЕНЦИАЛЬНОЙ ИНФОРМАЦИИ
}

\author{
Абрамова Любовь Андреевна \\ к.э.н., доцент
}

ФГБОУ ВО «Поволжский государственный университет сервиса»

Аннотация: Интерес к вопросам защиты информации в последнее время повысился, что связано с повышением роли информационных ресурсов в деятельности организации, расширением использования сетей и возможностей несанкционированного доступа $к$ хранимой и передаваемой информации. Развитие средств, методов и форм автоматизации процессов хранения и обработки информации и массовое применение персональных компьютеров делают информацию гораздо более уязвимой.

Ключевые слова: Информационные ресурсы, защита информации, несанкционированный доступ к информации, конфиденциальная информация.

\section{MODELING OF METHODS \\ OF UNAUTHORIZED ACCESS TO SOURCES OF CONFIDENTIAL INFORMATION}

\author{
Lyubov Abramova \\ candidate of Economics, Associate Professor \\ Volga State University of Service
}

\begin{abstract}
Interest in information security issues has recently increased, which is associated with the increasing role of information resources in the activities of the organization, the expansion of the use of networks and the possibility of unauthorized access to stored and transmitted information. The development of means, methods and forms of automation of the processes of storing and processing information and the massive use of personal computers make information much more vulnerable.

Key words: Information resources, information protection, unauthorized access to information, confidential information.
\end{abstract}


Несанкционированный доступ к информации - это доступ к данным, который нарушает правила разграничения доступа с реализацией определенных средств которые являются средствами вычислительной техники или автоматизированными системами.

К основным способам несанкционированного доступа к информации относятся: склонение к сотрудничеству; инициативное сотрудничество; выпытывание, выведывание; подслушивание; наблюдение; хищение; копирование; подделка; уничтожение; незаконное подключение; перехват; подделка; уничтожение; незаконное подключение; негласное ознакомление; фотографирование.

По мнению экспертов, такой перечень есть не пересекаемым и независимым на определенном уровне абстракции. Он позволяет рассмотреть определенное множество выборок таких методов вместе. В табл. 1 показана обобщенная модель способов несанкционированного доступа к источникам конфиденциальной информации.

Таблица 1

Модель способов несанкционированного доступа к источникам конфиденциальной информации

\begin{tabular}{|c|c|c|c|c|c|c|c|c|c|c|c|c|c|c|c|}
\hline \multirow[b]{2}{*}{ Источники } & \multicolumn{15}{|c|}{ Способы } \\
\hline & 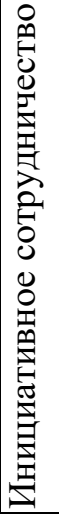 & 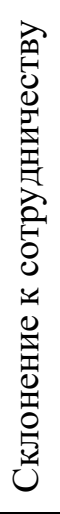 & 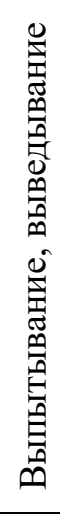 & 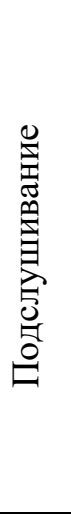 & 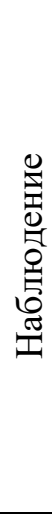 & 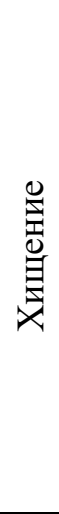 & 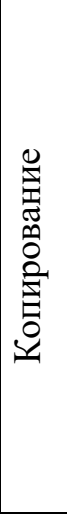 & 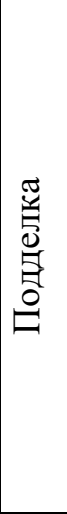 & 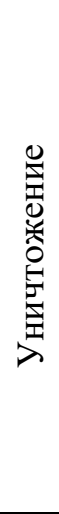 & 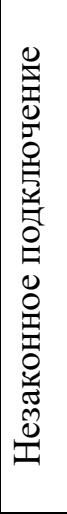 & 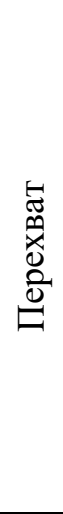 & 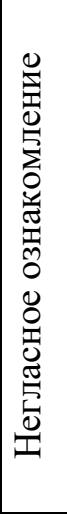 & 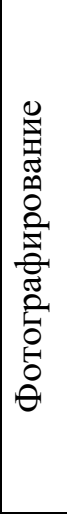 & 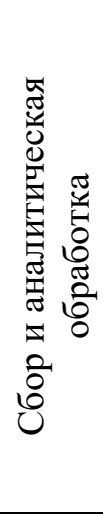 & 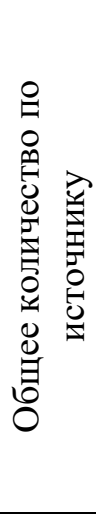 \\
\hline Люди & + & + & + & + & + & + & & + & + & & & + & + & & 10 \\
\hline Документы & & & & & + & + & + & + & + & & + & + & + & + & 9 \\
\hline Публикации & & & & & & & & + & & & & + & & + & 3 \\
\hline $\begin{array}{l}\text { Технические } \\
\text { носители }\end{array}$ & & & & & & + & + & + & + & & & & & + & 5 \\
\hline $\begin{array}{l}\text { Технические } \\
\text { средства ОПД }\end{array}$ & & & & + & & & & & + & + & + & & & & 4 \\
\hline $\begin{array}{l}\text { Технические } \\
\text { средства АСОД }\end{array}$ & & & & + & + & + & + & + & + & + & + & + & + & & 10 \\
\hline Продукция & & & & & + & + & + & + & + & & & + & + & & 7 \\
\hline Отходы & & & & & & + & & & & & & & & + & 2 \\
\hline Итого & 1 & 1 & 1 & 3 & 4 & 6 & 4 & 6 & 6 & 2 & 3 & 5 & 4 & 4 & 50 \\
\hline
\end{tabular}


Кроме того, способы несанкционированного доступа напрямую связанны с особенностями источника конфиденциальных данных.

Степень опасности способа несанкционированного доступа оценивается по нанесенному ущербу. Поскольку информация сегодня имеет свою цену, то сам факт приобретения информация приравнивается к получению денег. Злоумышленник преследует три цели: 1) получить данные для конкурентов и продать; 2) изменить данные в информационной сети; 3) уничтожить данные.

Любая электронная система, которая содержит совокупность узлов, элементов и проводников и обладает при этом источниками информационного сигнала - есть каналами утечки конфиденциальной информации. Способы несанкционированного доступа и каналы утечки объективно связанны. Варианты связей показаны в табл. 2.

Таблица 2

Взаимосвязь способов несанкционированного доступа и каналов утечки информации

\begin{tabular}{|l|c|c|c|c|}
\hline $\begin{array}{l}\text { Способ несанкционированного } \\
\text { доступа }\end{array}$ & $\begin{array}{c}\text { Визуальный } \\
\text { канал утечки }\end{array}$ & $\begin{array}{c}\text { Акустический } \\
\text { канал утечки }\end{array}$ & $\begin{array}{c}\text { Электромагнитный } \\
\text { канал утечки }\end{array}$ & $\begin{array}{c}\text { Материальный } \\
\text { канал утечки }\end{array}$ \\
\hline Подслушивание & & + & + & \\
\hline Визуальное наблюдение & + & & + & + \\
\hline Хищение & & & + & + \\
\hline Копирование & & & + & + \\
\hline Подделка & & + & + & \\
\hline Незаконное подключение & & + & & \\
\hline Перехват & & & & + \\
\hline Фотографирование & + & & & \\
\hline Итого & & & & + \\
\hline
\end{tabular}

От каждого источника образуется канал утечки данных, при этом его конкретные параметры изучаются и испытываются способы атак в лабораториях. Действия могут быть активными и пассивными. К пассивным относят реализацию технических каналов утечки информации без прямого контакта или подключения. Способы обычно ориентированы на получение данных. Активные методы подключаются к линиям связи. Линии связи могут быть:

- Проводные (волоконно-оптические).

- Беспроводные (Wi-Fi). 
Зачастую в качестве линий связи используют телефонные линии или оптоволоконные линии. Также есть системы прослушивания линий, которые не требуют прямого контакта с телефонной линией. Такие системы используют индуктивные методы съема данных. Такие системы не имеют широкого применения, так как они сильно большие из-за содержания несколько каскадов усиления слабого сигнала и в добавок внешний источник питания.

Но на сегодня линии оптоволокна имеют более широкий спектр реализации. Информация по такому каналу передается в виде пульсирующего светового потока, на который не влияют магнитные и электрические помехи. Также по такому каналу тяжелее перехватить данные, что повышает безопасность передачи. При этом скорость передачи достигает Гигабайт/секунду.

Транспортировка данных с помощью высокочастотных СЧВ и УКВ диапазонах дает возможность реализовать передачу информацию и компьютерную сеть там, где положить обычный проводные каналы есть сложно. В таких каналах связи передача информации возможно со скорость до 2 Мбит/с. При этом есть вероятность помех и перехвата информации. Перехват данных работает на основе перехвата электромагнитных излучений $\mathrm{c}$ дальнейшем анализом и расшифровывания. Перехват информации по таким каналам имеет свои особенности:

- данные можно получить без прямого контакта с источником;

- на сигнал не влияет ни время года/суток;

- прием данных проходит в реальном времени;

- перехват реализуется скрытно.

- дальность перехвата ограничена только характеристикой волн распространения.

\section{Список литературы}

1. ГОСТ Р 51275-2006 Защита информации. Объект информатизации. Факторы, воздействующие на информацию. Общие положения [Электронный pecypc] // КонсультантПлюс. - Режим доступа: http://www.consultant.ru/

2. ГОСТ 50922-2006 «Информационные технологии. Основные термины и определения в области технической защиты информации» [Электронный ресурс]//КонсультантПлюс. Режим доступа: http://www.consultant.ru/. 
3. ГОСТ Р 52069.0-2003 Защита информации. Система стандартов. Основные положения [Электронный ресурс] // КонсультантПлюс. - Режим доступа: http://www.consultant.ru/

4. ГОСТ Р 52447-2005 Защита информации. Техника защиты информации. Номенклатура показателей качества [Электронный ресурс] // КонсультантПлюс. - Режим доступа: http://www.consultant.ru/

5. Баранова, Е. К. Информационная безопасность. История специальных методов криптографической деятельности [Текст]: Учебное пособие / Баранова Е.К., Бабаш А.В., Ларин Д.А. Москва :ИЦ РИОР, НИЦ ИНФРА-М, 2019. 236 с.

(C) Л.А. Абрамова, 2021 